\title{
Influenza A H5N1 and HIV co-infection: case report
}

\author{
Annette Fox ${ }^{* 1,2}$, Peter Horby 1,2, Nguyen Hong Ha³, Le Nguyen Minh Hoa' ${ }^{1}$ Nguyen Tien Lam³, Cameron Simmons ${ }^{2,4}$, \\ Jeremy Farrar2,4, Nguyen Van Kinh ${ }^{3}$ and Heiman Wertheim 1,2,5
}

\begin{abstract}
Background: The role of adaptive immunity in severe influenza is poorly understood. The occurrence of influenza A/ H5N1 in a patient with HIV provided a rare opportunity to investigate this.

Case Presentation: A 30-year-old male was admitted on day 4 of influenza-like-illness with tachycardia, tachypnea, hypoxemia and bilateral pulmonary infiltrates. Influenza A/H5N1 and HIV tests were positive and the patient was treated with Oseltamivir and broad-spectrum antibiotics. Initially his condition improved coinciding with virus clearance by day 6 . He clinically deteriorated as of day 10 with fever recrudescence and increasing neutrophil counts and died on day 16. His admission CD4 count was 100/ul and decreased until virus was cleared. CD8 T cells shifted to a CD27+CD28- phenotype. Plasma chemokine and cytokine levels were similar to those found previously in fatal H5N1.

Conclusions: The course of H5N1 infection was not notably different from other cases. Virus was cleared despite profound CD4 T cell depletion and aberrant CD8 T cell activation but this may have increased susceptibility to a fatal secondary infection.
\end{abstract}

\section{Background}

Influenza $\mathrm{A} / \mathrm{H} 5 \mathrm{~N} 1$ infection is characterized by high viral loads, overproduction of pro-inflammatory cytokines and chemokines, direct lung tissue destruction, pulmonary oedema and extensive inflammatory infiltration [1$3]$. The prevailing view is that alveolar damage is the primary pathology leading to acute respiratory distress, multiple organ dysfunction syndrome and death [3]. Likewise, 2009 H1N1 infection can cause acute respiratory distress syndrome and death in previously healthy young adults very similar to the clinical syndrome seen in H5N1 [4].

It remains unclear whether lung pathology in severe influenza is a direct consequence of high viral loads and/ or of ensuing inflammatory responses. The involvement of innate versus adaptive immunity in inflammation or controlling viremia is also poorly defined. Further understanding of the pathological processes is necessary to develop interventions that prevent severe lung disease. The occurrence of H5N1 infection in a patient with HIV infection offered a unique opportunity to study the path-

\footnotetext{
*Correspondence: afox@oucru.org

1 Oxford University Clinical Research Unit Viet Nam, Wellcome Trust Major Overseas Program, National Hospital of Tropical Diseases, 78 Giai Phong Road, Dong Da, Ha Noi, Viet Nam

Full list of author information is available at the end of the article
}

ological and immunological process when adaptive immunity is impaired.

\section{Case presentation}

In February 2009 a 30-year-old male was admitted to our hospital with a four-day history of fever, cough and increasing difficulty breathing. Three days prior to illness onset he had slaughtered, prepared and consumed a duck that was the last survivor of a household flock of ten birds, which had died over the preceding week. Close contacts did not report recent respiratory illness and the patient had no known chronic health conditions. On admission the patient was febrile, tachycardic, tachypneic and hypoxemic (Figure 1). Chest $\mathrm{x}$-ray showed bilateral pulmonary infiltrates and an ultrasound revealed a right pleural-effusion. A throat swab was positive for influenza A/H5N1 by a real time RT-PCR protocol described elsewhere [2] but the cycle threshold (CT) value was 35 (Figure 1), indicative of low viral loads. Viral RNA was not detected in plasma. HIV antibody and/or antigen tests were performed as per routine practice in the admitting hospital. Determine HIV-1/2 rapid test (Abbott Laboratories), Genscreen ULTRA HIV Ag-Ab (BioRad) and SFD HIV 1/2 (Fujirebio) tests were positive. HIV branched DNA load was 510 copies/ml (Quantiplex HIV RNA 2.0 Assay, Chiron Corporation, USA). The patient was com- 
menced on supplemental oxygen by face mask, Oseltamivir phosphate (150 $\mathrm{mg}$ bd), broad-spectrum antibiotics (Table 1) for suspected bacterial co-infection and high dose co-trimoxazole for possible Pneumocystis jiroveci infection. Methylprednisolone was given $40 \mathrm{mg}$ once a day from days 5 to 8 and $20 \mathrm{mg}$ on days 9 and 10 of illness.

At admission, clinical and laboratory signs were similar in severity to those reported previously for fatal $\mathrm{H} 5 \mathrm{~N} 1$ patients (Figure 1). The patient's condition improved over the next days coinciding with virus clearance but began to deteriorate again from day 10 of illness with a recrudescence of fever (Figure 1). Deterioration coincided with increasing neutrophil counts and CRP levels (Figure 1). Fluconazole was given from day 10 and the supplemental oxygen flow rate increased. Sputum and blood obtained on day 4 and 10 were assessed by smear and/or culture for bacteria and fungi but pathogenic organisms were not detected (Table 2). Aspergillus fumigatus was cultured from tracheal aspirate obtained on day 14, and fluconazole was replaced with itraconazole. Chest $\mathrm{x}$-ray on day 14 showed marked bilateral infiltrates and pleural effusions (Figure 2). The patient was intubated and ventilated on day 15 of illness. The patient died on day 16 with respiratory and renal failure.

Blood samples were available for immunological assessment until day 7 of illness. CD4 lymphopenia was marked (Figure 1) with a CD4 count of $100 / \mu \mathrm{l}$ and a CD4:CD8 ratio of 0.16 at admission, which is lower than previously reported for any H5N1 case [2]. CD4 and CD8 counts decreased until virus was cleared (Figure 1). The percentage of CD8 T cells expressing activation markers including HLA-DR (Figure 1) increased to reach levels at least 10 times higher than normal [5]. At admission $50 \%$ of CD8 T cells had a fully differentiated (CD27-CD28-) phenotype but this decreased with a concomitant increase in the percentage with an intermediate differentiation (CD27+CD28-) phenotype (Figure 1).

Chemokine and cytokine levels were measured using cytometric bead array kits (Becton Dickinson). MIG

Table 1: Antibiotics and antifungals given

\begin{tabular}{lc}
\hline Drug name & Days of illness \\
\hline Ceftazidine & $4-10$ \\
Levofloxacin & $4-14$ \\
Cotrimoxazole & $5-16$ \\
Imipenem/Cilastatin & $10-14$ \\
Fluconazole & $10-14$ \\
Itraconazole & $14-16$ \\
Cefperazone-sulbactam & $14-16$ \\
\hline
\end{tabular}

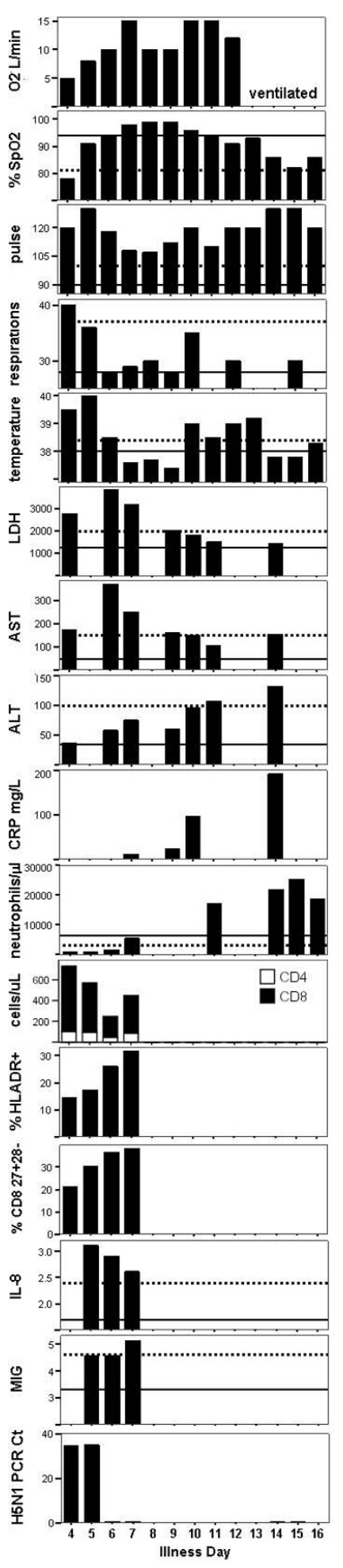

Figure 1 Clinical and laboratory findings by day of illness. Dashed and solid lines represent reported values for fatal and surviving H5N1 patients, respectively $[2,8,9]$. \%HLADR+ is for the the CD8 T cell subset. Cytokines and chemokines are reported as $\log 10 \mathrm{pg} / \mathrm{ml}$. 
Table 2: Laboratory tests for co-infection

\begin{tabular}{|c|c|c|c|}
\hline Illness Day & Specimen & Test & Result \\
\hline 4 & blood & culture & negative after 5 days \\
\hline \multirow[t]{2}{*}{4} & sputum & smear and Ziehl-Neelsen stain & negative \\
\hline & & culture for bacteria and fungi & Candida albicans \\
\hline 4 & $\mathrm{~N} / \mathrm{A}$ & Mantoux/PPD skin test & negative \\
\hline 10 & blood & culture & negative after 5 days \\
\hline 10 & sputum & culture for bacteria and fungi & Candida albicans \\
\hline 13 & blood & culture & negative after 5 days \\
\hline \multirow[t]{3}{*}{14} & tracheal aspirate & smear for fungi & positive \\
\hline & & smear and Ziehl-Neelsen stain & negative \\
\hline & & culture for bacteria and fungi & Candida albicans Aspergillus fumigatus \\
\hline
\end{tabular}

(CXCL9), IL-8 (Figure 1), IP-10 (CXCL10), MCP-1 (CCL2), IL-6 and IFN- $\gamma$ (not shown) concentrations were increased to levels similar to those found previously in patients with fatal H5N1. IL-8, MCP-1 and IL-6 levels declined from day 5 to 7 whereas MIG and IP-10 increased.

\section{Conclusions}

To our knowledge only one other patient with documented HIV and H5N1 co-infection has been reported and details of the clinical course in this patient have not been published [6].

Patients with immune compromise including those with HIV are at higher risk of complications associated with seasonal influenza [7]. This may not translate to highly pathogenic $\mathrm{H} 5 \mathrm{~N} 1$ which has been fatal in the majority of previously healthy patients. Although early clinical and laboratory findings were similar to those of other fatal $\mathrm{H} 5 \mathrm{~N} 1$ patients $[2,6,8,9]$, the patient showed a transient clinical improvement and a relatively delayed time to death, which was accompanied by signs of secondary pneumonia. In addition, viral loads were relatively low with no virus detection in plasma, unlike some fatal cases described previously $[2,6,8,9]$ suggesting that $\mathrm{H} 5 \mathrm{~N} 1$ viral clearance was not compromised by HIV co-infection. $\mathrm{H} 5 \mathrm{~N} 1$ can be cleared without antivirals and there is little benefit of Oseltamivir after day 6 of illness $[9,10]$. However early control of viral load appears to be impor- tant because survival rates are highest in patients treated earliest [10]. Thus, the contribution of Oseltamivir may have been negligible in this patient because viral loads were relatively low prior to administration. Lymphopenia is common in $\mathrm{H} 5 \mathrm{~N} 1$ patients $[2,6,9]$ and low CD3 counts and CD4:CD8 ratios have been reported [2]. We can not determine if immune compromise preceded influenza A/ $\mathrm{H} 5 \mathrm{~N} 1$ infection in this patient. Investigation of AIDS defining illnesses was not exhaustive because the patient was reported to have been healthy and the presenting symptoms and rapid onset of illness were consistent with the confirmed diagnosis of $\mathrm{H} 5 \mathrm{~N} 1$. We can not exclude the possibility of $P$. jirovecci or mycobacterial co-infection. CD4 counts and CD4:CD8 ratios were lower than we have seen in other $\mathrm{H} 5 \mathrm{~N} 1$ patients (unpublished findings). This suggests that CD4 T cells may not be required for viral clearance consistent with findings that CD8 T cells are more important for survival from highly virulent influenza infection in mice [11]. The patient maintained substantial numbers of peripheral CD8 T cells and a large fraction became activated, but the concomitant shift to a CD27+CD28- phenotype raises doubts about their antiviral function. This phenotype is associated with CD8 T cells that proliferate but lack cytotoxic function and accumulate in progressive HIV infection [12]. Chemokine and cytokine levels were high as in other fatal H5N1 cases and may account for the severity of the early pneumonia. The prevailing view is that excessive cytokine and chemokine 
release are secondary to high viral loads [2], whereas viral loads were low in this patient. Although HIV infection is also associated with increased expression of proinflammatory cytokines $[13,14]$, levels tend to be lower than found here [15], even with co-presentation of pneumocystis pneumonia, bacterial pneumonia or mycobacteriosis, and IFN- $\gamma$ expression is often decreased [13]. Levels of IL-8, MCP-1, and IL- 6 also decreased with H5N1 viral load indicting that they are primarily induced by $\mathrm{H} 5 \mathrm{~N} 1$ infection. There has been no conclusive report of secondary infection accompanying $\mathrm{H} 5 \mathrm{~N} 1$ whereas secondary pneumonia may have caused a considerable fraction of the deaths from the highly pathogenic 1918 H1N1 strain and the current H1N1 2009 strain [16]. Findings in this patient including recrudescence of fever, rising CRP levels and neutrophilia were consistent with a secondary infection despite being treated with broad-spectrum antibiotics. A. fumigatus was detected in a tracheal aspirate suggestive of invasive pulmonary aspergillosis. Corticosteroid adminsitration may have contributed to the presumed development of invasive pulmonary aspergillosis [17], but there have been numerous reports of invasive pulmonary aspergillosis developing after influenza A infection in which $\mathrm{T}$ cell lymphopenia occurred $[18,19]$. None these patients had HIV and few received corticosteroids indicating the influenza $\mathrm{A}$ associated immune suppression may be sufficient for the development of invasive pulmonary aspergillosis. In conclusion the course of H5N1 infection in this case was not notably different in the presence of HIV co-infection but it is possible that HIV co-infection and profound CD4 T cell depletion increase susceptibility to secondary infection. The findings suggest that $\mathrm{CD} 4 \mathrm{~T}$ cells may not be required for $\mathrm{H} 5 \mathrm{~N} 1$ virus clearance.

\section{Consent}

The admitting hospital approved the use of patient samples and data and written informed consent was obtained from the next of kin for publication of this case report. A copy of the written consent is available for review by the Editor-in-Chief of this journal.

\section{Competing interests}

The authors declare that they have no competing interests.

\section{Authors' contributions}

AF designed and conducted immunological assessments and drafted the manuscript; PH coordinated the collection of clinical information and helped draft the manuscript; NHH and NTL were the reference physicians during the in-hospital management of this case; LNMH carried out molecular diagnostics and immunological assessments; CS and JF participated in study design and analysis; NVK helped coordinate the collection of patient information; HW coordinated virology and helped draft the manuscript. All authors read and approved the final manuscript.

\section{Acknowledgements}

This work was funded by the Wellcome Trust UK Major Overseas Programme and The South East Asia Infectious Diseases Clinical Research Network. We thank Ngoc Nghiem My and Rogier Van Doorn for performing the HIV viral load determination.
Figure $\mathbf{2}$ Chest X-ray images. The illness day is shown in the bottom left corner of each image. 


\section{Author Details}

'Oxford University Clinical Research Unit Viet Nam, Wellcome Trust Major Overseas Program, National Hospital of Tropical Diseases, 78 Giai Phong Road, Dong Da, Ha Noi, Viet Nam, ${ }^{2}$ Centre for Tropical Medicine, Nuffield Department of Clinical Medicine, University of Oxford, Churchill Hospital, Old Road, Oxford OX3 7L, UK, ${ }^{3}$ National Hospital of Tropical Diseases, 78 Giai Phong Road, Dong $\mathrm{Da}$, Ha Noi, Viet Nam, ${ }^{4}$ Oxford University Clinical Research Unit Viet Nam, Wellcome Trust Major Overseas Program, Hospital for Tropical Diseases, 190 Ben Ham Tu Street, District 5, Ho Chi Minh City, Viet Nam and 5South East Asia Infectious Diseases Clinical Research Network, Jl Diponegoro no 69, Jakarta, 10430, Indonesia

Received: 1 March 2010 Accepted: 14 June 2010

Published: 14 June 2010

\section{References}

1. Peiris JS, Yu WC, Leung CW, Cheung CY, Ng WF, Nicholls JM, Ng TK, Chan KH, Lai ST, Lim WL, et al:: Re-emergence of fatal human influenza A subtype H5N1 disease. Lancet 2004, 363(9409):617-619.

2. de Jong MD, Simmons CP, Thanh TT, Hien VM, Smith GJ, Chau TN, Hoang DM, Chau NV, Khanh TH, Dong VC, et al: Fatal outcome of human influenza $A(\mathrm{H} 5 \mathrm{~N} 1)$ is associated with high viral load and hypercytokinemia. Nat Med 2006, 12(10):1203-1207.

3. Gambotto A, Barratt-Boyes SM, de Jong MD, Neumann G, Kawaoka Y: Human infection with highly pathogenic $\mathrm{H} 5 \mathrm{~N} 1$ influenza virus. Lancet 2008, 371(9622):1464-1475.

4. Perez-Padilla R, de la Rosa-Zamboni D, Ponce de Leon S, Hernandez M, Quinones-Falconi F, Bautista E, Ramirez-Venegas A, Rojas-Serrano J, Ormsby $C E$, Corrales $A$, et al:: Pneumonia and respiratory failure from swine-origin influenza A (H1N1) in Mexico. N Engl J Med 2009, 361(7):680-689.

5. Miller JD, van der Most RG, Akondy RS, Glidewell JT, Albott S, Masopust D, Murali-Krishna K, Mahar PL, Edupuganti S, Lalor S, et al.: Human effector and memory CD8+ T cell responses to smallpox and yellow fever vaccines. Immunity 2008, 28(5):710-722

6. Chotpitayasunondh T, Ungchusak K, Hanshaoworakul W, Chunsuthiwat S, Sawanpanyalert P, Kijphati R, Lochindarat S, Srisan P, Suwan P, Osotthanakorn Y, et al:: Human disease from influenza A (H5N1), Thailand, 2004. Emerg Infect Dis 2005, 11(2):201-209.

7. Kunisaki KM, Janoff EN, et al:: Influenza in immunosuppressed populations a review of infection frequency, morbidity, mortality, and vaccine responses. Lancet Infect Dis 2009, 9(8):493-504.

8. Yu H, Gao Z, Feng Z, Shu Y, Xiang N, Zhou L, Huai Y, Feng L, Peng Z, Li Z, et al: Clinical characteristics of 26 human cases of highly athogenic avian influenza A (H5N1) virus infection in China. PLOS ONE 2008, 3(8):e2985.

9. Liem NT, Tung CV, Hien ND, Hien TT, Chau NQ, Long HT, Hien NT, Mai le Q, Taylor WR, Wertheim $\mathrm{H}$, et al.: Clinical features of human influenza $\mathrm{A}$ (H5N1) infection in Vietnam: 2004-2006. Clin Infect Dis 2009, 48(12):1639-1646.

10. Kandun IN, Tresnaningsih E, Purba WH, Lee V, Samaan G, Harun S, Soni E, Septiawati C, Setiawati T, Sariwati E, et al:: Factors associated with case fatality of human $\mathrm{H} 5 \mathrm{~N} 1$ virus infections in Indonesia: a case series. Lancet 2008, 372(9640):744-749.

11. Bender BS, Croghan T, Zhang L, Small PA Jr: Transgenic mice lacking class I major histocompatibility complex-restricted T cells have delayed viral clearance and increased mortality after influenza virus challenge. J Exp Med 1992, 175(4):1143-1145.

12. Barbour JD, Ndhlovu LC, Xuan Tan Q, Ho T, Epling L, Bredt BM, Levy JA Hecht FM, Sinclair E: High CD8+ T cell activation marks a less differentiated HIV-1 specific CD8+ T cell response that is not altered by suppression of viral replication. PLOS ONE 2009, 4(2):e4408.

13. Valdez H, Lederman MM: Cytokines and cytokine therapies in HIV infection. AIDS Clin Rev 1997:187-228.

14. Kedzierska K, Crowe SM: Cytokines and HIV-1: interactions and clinical implications. Antivir Chem Chemother 2001, 12(3):133-150.

15. Thea DM, Porat R, Nagimbi K, Baangi M, St Louis ME, Kaplan G, Dinarello CA, Keusch GT: Plasma cytokines, cytokine antagonists, and disease progression in African women infected with HIV-1. Ann Intern Med 1996, 124(8):757-762.

16. Bacterial coinfections in lung tissue specimens from fatal cases of 2009 pandemic influenza A (H1N1) - United States, May-August 2009. MMWR Morb Mortal Wkly Rep 2009, 58(38):1071-1074.
17. Garcia Garcia S, Alvarez C: Steroid treatment: risk factor for invasive pulmonary aspergillosis. Arch Bronconeumol 1998, 34(3):158-161.

18. Hasejima N, Yamato K, Takezawa S, Kobayashi H, Kadoyama C: Invasive pulmonary aspergillosis associated with influenza B. Respirology 2005 10(1):116-119.

19. Ohnishi T, Andou K, Kusumoto S, Sugiyama H, Hosaka T, Ishida H, Shirai K, Nakashima M, Yamaoka T, Okuda K, et al.: Two cases of successfully treated invasive pulmonary aspergillosis following influenza virus infection. Nihon Kokyuki Gakkai Zasshi 2007, 45(4):349-355.

\section{Pre-publication history}

The pre-publication history for this paper can be accessed here: http://www.biomedcentral.com/1471-2334/10/167/prepub

doi: $10.1186 / 1471-2334-10-167$

Cite this article as: Fox et al., Influenza A H5N1 and HIV co-infection: case report BMC Infectious Diseases 2010, 10:167

\section{Submit your next manuscript to BioMed Centra and take full advantage of:}

- Convenient online submission

- Thorough peer review

- No space constraints or color figure charges

- Immediate publication on acceptance

- Inclusion in PubMed, CAS, Scopus and Google Scholar

- Research which is freely available for redistribution
C Biomed Central 